\title{
A CRISE DA DEMOCRACIA SEGUNDO DERRIDA
}

\author{
THE CRISIS OF DEMOCRACY ACCORDING TO DERRIDA
}

Sérgio Luiz Bellei*

\begin{abstract}
RESUMO
Jacques Derrida entende a crise da democracia não em termos de um movimento histórico a ser superado por medidas corretivas, mas em termos de uma crise permanente provocada desde sempre por um sistema autoimune que ataca o organismo democrático a partir do seu interior. A forma privilegiada de combate a essa crítica permanente consiste na possibilidade de um porvir imprevisível e improgramável que foi objeto de questionamentos por representantes maiores da tradição marxista.
\end{abstract}

PALAVRAS-CHAVE: Crise. Democracia. Desconstrução. Jacques Derrida. Tradição marxista.

\begin{abstract}
Jacques Derrida sees the crisis of democracy not in terms of a historical movement to be overcome by compensatory actions, but in terms of a permanent crisis always already caused by an autoimmune system that attacks the democratic organism from the inside. The privileged way to resist this permanent crisis consists in the possibility of imagining an unprogrammed and unpredictable avenir that turned out to become the object of severe criticism by major representatives of the Marxist tradition.
\end{abstract}

KEYWORDS: Crisis. Democracy. Deconstruction. Jacques Derrida. Marxist tradition.

\section{INTRODUÇÃO}

Em ensaio dedicado ao estudo do conceito de "crise" no contexto da História das ideias, Reihart Koselleck e Michaela Richter (2006) alertam para a proliferação pouco precisa de sentidos do termo no momento presente, motivada particularmente pelo seu uso na mídia, e para o relativo rigor do seu uso no passado:

O conceito de "crise", que no passado tinha o poder de propor alternativas precisas, inevitáveis e inegociáveis, modificou-se a ponto de adaptar-se a quaisquer incertezas que se apresentem em um dado momento. Essa tendência ao vago e ao impreciso, contudo, pode bem ser entendida como um sintoma de uma crise história que não

\footnotetext{
*Professor Titular de Teoria Literária na Faculdade de Letras da UFMG. E-mail: sergiobellei50@gmail.com.
} 
pode ainda ser adequadamente avaliada. (KOSELLECK; RICHTER, 2006, p. 399, tradução nossa).

É nesse contexto contemporâneo que se pode falar, por exemplo, em "crise de autoconfiança" ou "especialista em crises". E o termo pode aplicar-se tanto a "conflitos", "revoluções" ou "inquietações" como a "situações ou sentimentos perturbadores" (KOSELLECK; RICHTER, 2006, p. 399). No presente trabalho, o conceito será entendido em seu sentido tradicional de um momento histórico de corrosão de valores estabelecidos que deve ser examinado com o propósito de obter soluções. A lógica que define a crise é, portanto, aquela de uma dinâmica de problema e solução programada. Foi assim que a entendeu Thomas Paine, em sua defesa da Revolução Francesa, apesar dos horrores que o movimento trouxe consigo. Resultado de uma corrupção sistêmica que infestou sistemas sociais durante séculos, a Revolução tornou-se necessária como remédio amargo para um futuro melhor. "A crise chegou, e não há escolha a não ser agir com determinação e vigor, ou então desistir de qualquer ação.” (PAINE, 1999, p. 283, tradução nossa). Há um movimento histórico que leva ao momento de crise e que deve ser historicamente retificado por uma ação moralmente responsável.

A democracia entra em crise sempre que o poder (krátos) do povo (dêmos) é comprometido, por exemplo, por forças ditatoriais, por fundamentalismos religiosos ou por terroristas. A crise clama por soluções que não tardam a chegar, como no caso exemplar do ataque às torres gêmeas do World Trade Center. Coube então à nação que mais visivelmente chamou a si a tarefa de realizar historicamente a prática dos ideais democráticos de, à sua maneira, estabelecer um plano de ação para defender a democracia contra seus inimigos. Como era de se esperar, o suposto resgate da democracia se fez por formas variadas de violência: as campanhas militares no Iraque e no Afeganistão e a criação de novas leis (Patriot Act). Nesse último caso, a democracia é afetada por um efeito colateral do ataque às torres: as liberdades e direitos pessoais são limitados e as regras de imigração alteradas. Mais recentemente, a democracia entra em crise não mais pela violência terrorista, mas pelos meios de comunicação social que, tendo incorporado as novas tecnologias digitais, tornam-se capazes de produzir um espaço de hiperconectividade com intensidade sem precedentes. Essa vasta rede de conexões, ou ciberespaço, é o ambiente propício para o incremento de outro inimigo clássico da democracia, ou seja, a demagogia, em que o poder do povo (dêmos) é subtraído pela ação de um líder mistificador (àgogôs). Mas já não se trata agora da 
demagogia tradicional, em que a manipulação das massas é feita por agentes humanos. Estes são agora substituídos por máquinas, ou algoritmos, que têm poder mais eficaz de manipulação em grande escala. Algoritmos utilizados por corporações como o Google ou o Facebook constituem hoje mecanismos mais poderosos de vigilância e controle do que aqueles desenvolvidos tradicionalmente por agentes governamentais. $\mathrm{O}$ poder antidemocrático do Big Brother imaginado por Orwel em 1984 é, comparativamente, pouco significativo. O aperfeiçoamento constante de algoritmos permite o processamento imediato de vastos bancos de dados coletados com ou sem a permissão daqueles que se conectam à rede e tornam possível a construção precisa de perfis individuais de consumidores e de seus desejos ou preferências. De posse de tais perfis, a máquina digital pode, com precisão cirúrgica, bombardear clientes específicos não com possibilidades de escolha, mas com escolhas prédeterminadas para atender a desejos. É óbvio que, na medida em que mais e mais indivíduos recorrem única ou prioritariamente a meios hegemônicos de comunicação (Google, Facebook) que só atendem a desejos, a esfera pública de tomada de decisões a partir de possibilidades torna-se comprometida, quer se trate, por exemplo, da escolha de produtos ou de políticos em eleições “democráticas”. Já não é impossível, hoje, alimentar um grande número de usuários única ou prioritariamente com "fake news" por eles desejados ou, o que produz os mesmos resultados, alimentá-los apenas com as notícias verdadeiras que querem consumir. A possibilidade tecnológica de atingir e manipular alvos específicos em grande escala ameaça, no momento histórico que costumamos chamar de pós-moderno, compromete a própria distinção tradicional entre o verdadeiro e o falso e, consequentemente, o processo decisório que é essencial para a democracia. Seria possível propor soluções para a poderosa manipulação tornada possível pelas tecnologias digitais de acúmulo e distribuição da informação? Há ainda quem pense que não é impossível retornar a um passado em que o verdadeiro jornalismo, por exemplo, podia oferecer notícias a partir de agentes humanos responsáveis. Seja como for, nesse caso, estamos ainda operando no paradigma de problema e solução programada para resolver crises.

\section{DEMOCRACIA E AUTOIMUNIDADE}

O uso da metáfora da "autoimunidade" em Derrida complica significativamente o paradigma de problema e solução no caso de democracias em crise. Em biologia, o sistema 
imunológico opera para proteger o organismo ameaçado por células ou antígenos. O sistema identifica os antígenos e produz anticorpos para destruí-los. Em casos de autoimunidade, o sistema imune torna-se disfuncional: identifica células do próprio organismo como invasoras e tenta destruí-las, como é o caso, dizem as ciências médicas, em certos casos de diabetes. Derrida tenta aplicar o conceito usado para o organismo vivo à organização social. Existe, em qualquer grupo social, uma força autoimune ou suicida que, operando mecânica e inevitavelmente, não depende das escolhas a serem feitas por membros da comunidade ou pela coletividade como um todo. Age espontaneamente contra a tendência que tem qualquer corpo social de se manter puro, intocável e incontaminado através do esforço imunizante que opera no contexto de problema e solução. Não se trata aqui, como seria no caso de uma gripe, em que o vírus pode ser identificado como um inimigo outro e externo a ser neutralizado. $\mathrm{O}$ outro aqui habita o interior do organismo e ataca a si mesmo, o que significa que o veneno, nesse caso, não se distingue do remédio. Não é por acaso que, mesmo nas ciências médicas, doenças causadas por complicações autoimunes são mais difíceis de serem identificadas e tratadas. Tudo se passa como se, na tentativa de atacar um invasor, o organismo acabasse por dar um tiro no pé.

Para Derrida, tanto o sistema imune quanto o autoimune estão presentes em qualquer corpo social, seja ele uma religião, uma etnia, ou uma nação. "Sentimo-nos autorizados" afirma o filósofo, "a falar de uma forma de lógica geral da autoimunidade. Essa lógica parecenos indispensável, hoje, para pensar as relações entre fé e conhecimento, religião e ciência" (DERRIDA, 2002, p. 80, tradução nossa). Em outro contexto, e sem referência a Derrida, David Noble mostrou que só aparentemente a fé é inimiga da ciência. Argumenta, em The Religion of technology, que o fascínio religioso com a ciência que caracteriza o homem da modernidade faz parte de uma tradição milenar que olha para a tecnologia na postura de adoração de quem espera resgatar o que se perdeu no paraíso adâmico. "A emergência da tecnologia ocidental como uma força histórica e a emergência da religião da tecnologia são os dois lados do mesmo fenômeno" (NOBLE, 1999, p. 9, tradução nossa). Se traduzirmos a tese para a proposta de autoimunidade em Derrida, na tentativa de imunizar-se contra a religião, a ciência produz um sistema autoimune em que o vírus da fé ataca o organismo científico. No caso dos dois exemplos de crise da democracia citados anteriormente, é também possível detectar forças autoimunes. Os terroristas que atacaram as torres gêmeas obtiveram treinamento para pilotar jatos utilizando o próprio organismo tecnológico norte-americano 
que tem, entre outras funções, a de supostamente proteger o sistema democrático. E o Patriot act, paradoxalmente, ataca a democracia para defendê-la. No caso da produção de fake news não custa lembrar que a tecnologia digital que tornou possível a hiperconectividade foi, em seus inícios, celebrada como capaz de promover processos de democratização porque, incentivando a mobilização de baixo para cima, tornaria possível a cidadãos ordinários neutralizar repressões institucionais e produzir mais transparência na política. Os governos tornar-se-iam mais transparentes porque atingidos por formas de cidadania mais participativa. Seria até mesmo possível subverter regimes autoritários. Celebrou-se, em passado recente, o papel revolucionário do Twitter e do Facebook na Primavera Árabe. No momento presente, esse otimismo já não pode sobreviver sem sua contrapartida: existe, ao seu lado, um pesadelo digital que compromete a democracia porque a tecnologia não tem simplesmente o poder de promover participação, mas também de vigiar e controlar os participantes.

Apresentada nesses termos, a lógica da autoimunidade parece uma força fundamentalmente negativa. Leitores familiarizados com exercícios de desconstrução, especialmente aqueles realizados pelo próprio Derrida, olhariam com suspeita a pureza dessa negação. É que o modus operandi da desconstrução tende rotineiramente a colocar em xeque a pureza dos elementos de pares binários e a enfatizar a ambivalência e a porosidade de fronteiras cada vez que se defronta com os binarismos do bem e do mal, do veneno e do remédio, ou do imune e do autoimune. Afirma Derrida, no mesmo ensaio citado acima:

[Não existe] comunidade que não cultive a sua própria autoimunidade, um princípio de autodestruição sacrificial que deixa em ruinas o princípio da autoproteção (aquele que tem por princípio manter intacta a sua própria integridade), e isso tendo em vista algum tipo de sobrevida espectral invisível. Essa confirmação que se questiona a si mesma mantém a comunidade autoimune viva, vale dizer, aberta para alguma coisa outra e que vai além de si mesma: o outro, o futuro, a morte, a liberdade, a chegada do amor do outro, o espaço e o tempo de uma messianidade espectral para além de qualquer messianismo. (DERRIDA, 2002, p. 87, tradução nossa).

O texto é um tour de force porque condensa em poucas linhas questões tratadas extensivamente em outros escritos de Derrida. Um comentário que realmente fizesse justiça a essa densidade discursiva seria impossível nos limites deste ensaio. A referência à espectralidade, por exemplo, remete imediatamente aos Espectros de Marx; a questão do "amor do outro" aos textos sobre a hospitalidade incondicional e à distinção entre o "outro" e o "Outro". Limito-me a comentar apenas, de forma esquemática, a questão da ambivalência 
do conceito de "autoimunidade" (que pode manter "a comunidade autoimune viva", em condição de liberdade e à espera do amor do outro mas, paradoxalmente, pode também levar à morte), apresentada no texto como inseparável de uma "messianidade espectral para além de qualquer messianismo". Como entender um messianismo sem messias?

O messianismo com messias é aquele exemplificado nas tradições judaica e cristã. Tem um nome próprio (messias, filho de Davi; Jesus, filho de Deus) e é programado para chegar ao futuro de boas novas do reino ou da unificação das tribos de Israel. Repete-se aqui o paradigma de problema e solução que indiquei no início como típico do enfrentamento tradicional de crises. No messianismo sem messias de Derrida, o messias é o Outro sem nome que está (ou não) por vir. Em The gift of death, Derrida (1995, p. 82-83, tradução nossa) explica o significado desse "Outro" em exame detalhado da expressão "todo outro é todo outro" (tout autre est tout autre). Longe de constituir apenas uma tautologia, a repetição do tout é entendida como uma heterologia radical: o segundo tout autre não repete o "qualquer outro" anterior. Significa, antes, o Outro total, singular e absoluto. Seria mais adequado traduzir a expressão por "qualquer outro é o Outro absoluto", ou seja, é aquele que, em sua singularidade, não pode ser conhecido ou programado em sua alteridade incomensurável. Difere radicalmente, portanto, daquele outro que, no encontro entre duas individualidades, conheço e fabrico a partir da minha percepção, e por quem sou também fabricado. Esse outro pode ter um nome e uma existência histórica, pode submeter-se ao cálculo e à previsibilidade. O Outro é infinito, escapa ao conhecimento, é imprevisível e incalculável. Associada a esse Outro, a autoimunidade pode abrir, em qualquer comunidade, a democrática inclusive, a possibilidade da chegada (ou não) de um futuro que está sempre por vir para além de qualquer programação.

\section{DEMOCRACIA E SOBERANIA}

Para Derrida, a autoimunidade opera desde sempre no contágio inevitável entre democracia e soberania, o que significa dizer que a democracia está em crise permanente. Derrida caracteriza o soberano nos termos clássicos propostos por Carl Schmitt: “define-se o soberano pela sua capacidade de decidir a respeito do regime de exceção [e ele tem] o direito de suspender a lei" (DERRIDA; ROUDINESCO, 2001, p. 151, tradução nossa). Nas 
democracias modernas, esse direito de suspender a lei pertence à instituição governamental ou ao seu líder. Em algumas democracias, o presidente da República exerce seu poder soberano, por exemplo, quando dá anistia a condenados por lei. Instituições governamentais que aplicam a pena de morte, ferindo o direito à vida do cidadão comum, também atuam acima da lei porque atribuem a si mesmas o monopólio da prática da violência que não é permitida aos governados. A soberania opera também entre nações mais ou menos poderosas na dimensão internacional. O poder soberano chama a si a tarefa de controlar suas fronteiras, excluir aqueles que não têm cidadania e proteger o território contra ameaças, terroristas inclusive. Mas pode também exercer esse poder para expansões territoriais, ferindo a "soberania" de nações menos poderosas em uma democracia global. É nesse contexto que uma supernação como os Estados Unidos exercem um papel soberano entre outros estados "soberanos" porque tem maior poder de controle no pouco democrático Conselho de Segurança da ONU. Nas palavras do próprio Derrida, em Voyous:

\footnotetext{
Como sempre, esses dois princípios, democracia e soberania, são ao mesmo tempo e sucessivamente indissociáveis e contraditórios entre si. Para que a democracia seja uma realidade, para que tenha um espaço para afirmar a sua ideia e tornar-se real, necessita do kratos (poder) do dêmos (povo) - no caso em pauta o dêmos global. Necessita, portanto, da soberania, ou seja, um poder maior do que todos os demais no mundo. (DERRIDA, 2003, p. 12, tradução nossa).
}

As democracias modernas são, portanto, aporéticas, condenadas que estão às contradições irredutíveis e insuperáveis entre as forças da imunização democrática e da autoimunidade soberana. Como não há democracia sem soberania, não pode esta última ser eliminada, já que sua destruição significaria o fim da própria democracia. E a sua supressão comprometeria também a própria condição da cidadania moderna e dos direitos humanos. Mais uma vez, estamos diante de uma realidade em que as fronteiras entre o veneno e o remédio são porosas. O que caracteriza o soberano não é apenas o poder, mas também a autonomia e a liberdade: “os direitos humanos exigem e pressupõem o ser humano enquanto soberano (igual, livre, autônomo)" (DERRIDA, 2003, p. 128, tradução nossa). E sem essa soberania tanto a liberdade de escolha como a possibilidade de decisões responsáveis deixariam de existir: "toda a axiomática essencial da responsabilidade e da decisão (ética, jurídica, política) fundamenta-se na soberania do sujeito, ou seja, na autodeterminação do indivíduo consciente (que é livre, autônomo, ativo, etc.)" (DERRIDA, 2002, p. XIX, tradução nossa). 
O impasse é evidente. De um lado, o sujeito soberano compromete ou pode comprometer a democracia. De outro, é indispensável para a existência do organismo democrático. Haveria uma forma de amenizar a ameaça permanente da soberania? A resposta da desconstrução é positiva pois tem o potencial para atuar em duas frentes: a desconstrução interna da soberania, ao mesmo tempo em que sua presença é garantida; e a desconstrução que preserva a soberania ao mesmo tempo em que altera a sua relação com o Outro. Desconstruir internamente a soberania do eu, seja ele pessoal ou estatal, significa questionar a sua suposta unidade e integridade:

No lugar de um sujeito consciente de si mesmo, respondendo de forma soberana perante a lei, podemos colocar a ideia de um "sujeito" dividido e diferenciado, que não pode ser reduzido a uma intencionalidade consciente e egológica. E um sujeito que só se estabelece aos poucos e com esforço, e ainda assim de forma imperfeita, estabilizando progressivamente a sua situação - ou seja, de forma não natural, essencialmente e para sempre instável - de heteronomia (DERRIDA, 2001, p. 286, tradução nossa).

A desconstrução da autonomia do sujeito soberano deve ser acompanhada pela desconstrução de sua relação com o Outro. Em Philosophy in a Time of terror, a questão é trabalhada em termos da hospitalidade condicional e incondicional. Como no caso da contaminação inevitável entre democracia e soberania, as duas formas de hospitalidade são “ao mesmo tempo heterogêneas e indissociáveis" (BORRADORI, 2003, p. 129, tradução nossa). Na hospitalidade condicional, há sempre a intervenção de uma força soberana em que o hospedeiro restringe, ao mesmo tempo em que pratica, a hospitalidade para o hóspede. E restringe porque, nas palavras de Derrida (2003, p. 128, tradução nossa), mantém o controle “dos limites da ... casa e da... soberania". Como no caso da nação soberana e do eu soberano, mesmo na casa do hospedeiro mais generoso a soberania é exercida, e limites são estabelecidos para o comportamento do hóspede que, longe de estar livre para fazer o que quiser, deve seguir as regras da casa e ser, por assim dizer, domesticado pelo soberano. Essa hospitalidade condicional pertence ao tempo histórico do aqui e agora. Já a hospitalidade incondicional é impensável no aqui e agora: existe, se é que sua existência é possível, em um futuro que não pode ser conhecido ou programado. Só pode ser pensada no contexto de um "evento", no sentido que Derrida atribui ao termo:

O evento é aquilo que chega e, ao chegar, chega para surpreender-me, para surpreender e suspender o entendimento. O evento é antes de tudo aquilo que, em 
primeiro lugar, eu não compreendo. Ou melhor, o evento é, em primeiro lugar, que eu não compreendo. Consiste nesse que, que eu não compreendo: aquilo que eu não compreendo $\mathrm{e}$, antes de tudo, que eu não compreendo, o fato de eu não compreender: minha incompreensão (DERRIDA, 2003, p. 90, tradução nossa).

Absolutamente incompreensível, o evento escapa a todo e qualquer conhecimento prévio, não pode ser imaginado com base nos condicionamentos existentes na história passada ou no momento presente. Nesse contexto, a hospitalidade incondicional seria aquela em que o hospedeiro de antemão aceita receber o hóspede sem condições, quer se trate das condições conhecidas da hospitalidade condicional, quer se trate de todo e qualquer conhecimento do comportamento do hóspede. Sua condição é aquela de um ser sem nome, desconhecido e inimaginável. Estamos aqui diante de uma proposta de assimetria radical entre o passado e o presente, de um lado, e o futuro, de outro. O senso comum nos prepara apenas para pensar o futuro em termos de uma simetria com o presente e o passado: a história se repete, o que vai acontecer já aconteceu de forma análoga no passado, e é possível; portanto, imaginar, antecipar, conhecer e até mesmo programar o futuro, talvez evitando os erros anteriormente cometidos. Para Derrida, esse futuro não constitui um evento, mas uma repetição. No evento, a assimetria com o que passou permite a experiência do imprevisível e do impossível. Para o bem, ou para o mal. De qualquer forma, o futuro assim pensado constitui a experiência do novo absoluto que, mais vigoroso que qualquer planejamento, poderia motivar a mudança e a renovação da democracia em uma crise histórica em que qualquer solução no contexto do paradigma empírico de problema e solução é necessariamente marcado por uma precariedade que dificulta avanços.

\section{A DEMOCRACIA POR VIR}

Levada às últimas consequências, a distinção entre um futuro sem messias que aguarda o evento imprevisível e um futuro sem evento em que o cálculo e a programação no presente desenham um futuro previsível significa que, no segundo caso, o que ocorre é a permanência do mesmo. Não há mudanças porque inviabilizou-se a chegada do Outro. E essa permanência do mesmo, se aceitarmos a premissa de que a democracia imuniza-se ao mesmo tempo em que se autoimuniza, está permanentemente em guerra consigo mesma. É essa aporia do imune e do autoimune que, para Derrida, complica a apressada distinção feita pelo 
governo norte-americano entre estados democráticos e estados renegados após o ataque às torres gêmeas em setembro de 2001.

O ditador ou o estado ditatorial que atuam fora da legalidade democrática são, em momentos críticos, associados ao animalesco. A reputação de Sadam Husseim, durante a guerra do golfo, como "a fera de Bagdad", é o exemplo mais visível dessa separação entre a democracia como força humanizante e barbárie desumanizada. Na prática desconstrucionista, contudo, o conceito de renegado torna-se ambíguo: o renegado, quer se trate de um indivíduo ou de um estado, pode ser um delinquente, mas pode também ser uma força de resistência quando desafia o poder do estado e propõe uma soberania alternativa em relação ao estado que se autoproclama legal. No contexto de um regime democrático em dimensão global, um estado declarado renegado a partir da perspectiva soberana de uma supernação como os Estados Unidos pode bem constituir uma força autoimunizante capaz de subverter a lei do mais forte. Em Voyous, Derrida cita Robert Litwak, secretário do conselho de segurança na administração de Bill Clinton: "um estado renegado é basicamente qualquer um que os Estados Unidos dizem que é” (DERRIDA, 2003, p. 96). A violência soberana manifesta-se aqui afirmando a lei do mais forte, o que constitui uma violação de ideais democráticos e faz dos Estados Unidos também um estado renegado:

\footnotetext{
Essa "lógica" [do conceito de soberania] deixa claro que, a priori, os estados que tem potencial para, ou que estão em um estado de guerra contra estados renegados são, eles próprios, na sua mais legítima soberania, estados renegados que abusam do seu poder. No momento em que existe soberania, existe também o abuso do poder e o estado renegado. O abuso é a lei do uso; é como se a própria lei constituísse uma "lógica" de soberania que só pode reinar pela recusa de partilhar.... Só pode tender para a hegemonia imperial. (DERRIDA, 2003, 145-146, tradução nossa).
}

Não há, portanto, uma democracia que não seja, ao mesmo tempo, um estado renegado, muito embora nem todos os estados sejam renegados da mesma forma, ou com a mesma intensidade. A relativização é importante para que não se pense que Derrida coloca em pé de igualdade o terrorismo islâmico e o estado democrático norte-americano. Em entrevista a Giovanna Borradori, Derrida aponta para a distinção necessária entre a democracia contaminada pela soberania e o fundamentalismo não democrático, o que lhe permite afirmar que "as ações e o discursos de Bin Laden não se abrem para nenhum futuro e.... não têm futuro" (BORRADORI, 2003, p. 113, tradução nossa). Ao contrário de democracias, o 
fundamentalismo programa o futuro em termos do passado e do presente e não pode, portanto, admitir o imprevisível que está por vir.

Incapaz de resolver suas tensões internas e contradições, a democracia não existe no presente e deve esperar (ou não), no aqui e agora, por sua chegada ao que está por vir. Mas é importante insistir: o porvir em Derrida não é um horizonte de possibilidades que, vislumbrado do presente, sinaliza para que caminhemos em sua direção. É antes a imprevisível chegada do evento que escapa ao conhecimento e que, justamente em função dessa imprevisibilidade, afeta o presente enquanto aquela ruptura e perturbação paradoxalmente tornada possível pela autoimunidade. Uma democracia absolutamente imune a todos os males seria soberana e imutável, mas também desprovida de vida. É a ameaça da autoimunidade que instala na democracia uma fratura que se abre para o porvir e para o seu potencial de renovação.

\section{O PORVIR MILAGROSO E A URGÊNCIA DO PRESENTE}

O conceito do "porvir" em Derrida depende fundamentalmente do conceito de "evento". O porvir é a chegada do evento, ou seja, daquilo que é inconcebível, não conceituável, impossível de ser antecipado. É, portanto, a chegada do impossível, já que o possível pode ser conceituado antecipadamente. Richard Terdiman argumenta que, nesse sentido, o "evento" não pode ser diferenciado do "milagre" sem autor, contanto que se entenda este último termo não em termos valorativos, mas técnicos: o milagre é um "processo que não pode ser explicado por nenhum mecanismo social ou natural e que interfere no fluxo temporal sem que, contudo, possa ser organizado ou planejado" (TERDIMAN, 2007, p. 433, tradução nossa); escapa, portanto, ao controle de qualquer agente histórico e paralisa qualquer ação. É essa impossibilidade da ação e da vontade humana de atuar sobre o milagre que preocupa os críticos do conceito de porvir em Derrida. Estou paralisado e incapaz de agir diante do milagre porque ele está fora da história secular. Sou impotente diante do evento e não posso mudar o curso da história. Sou impotente para responder à urgência história de mudança acionada pelo homem. O evento, portanto, não é pensável no contexto no paradigma de problema e solução mencionado antes, como prática usual de resolver crises. Convida ao quietismo. 
Essa crítica ao milagre do evento aparece com vigor no volume dedicado a apreciações feitas sobre Os Espectros de Marx por críticos de orientação marxista, entre eles Terry Eagleton, Fredric Jameson e Pierre Macherey. A julgar pela resposta irada de Derrida, expressa no ensaio que fecha o volume e que tem como título "Marx \& Sons", pertence a Terry Eagleton a crítica mais contundente. Para Eagleton, a atenção tardia dada a Marx por Derrida constitui uma proposta de "Marxismo sem Marxismo", ou seja, um marxismo espectral que propõe uma alternativa pouco significativa diante da exortação de Marx sobre a necessidade de mudar radicalmente o mundo ativando, na história do aqui e agora, uma luta sem trégua a favor da "solidariedade, da organização e da ação política calculada" (EAGLETON, 2008, p. 84, tradução nossa). E há um preço alto a pagar por essa substituição do combate na história por uma "retórica filosófica" sobre espectros e messianismos sem messias:

\begin{abstract}
Se Derrida pensa, como parece de fato pensar, que pode existir qualquer socialismo eficaz sem organização, aparatos e doutrinas e programas aparentemente bem estruturados, então ele nada mais é do que uma vítima de uma fantasia acadêmica que de alguma forma confundiu-se com um antisstalinismo esclarecido.... A verdade é que ele pouco se preocupa com um socialismo eficaz. Preocupada com deslizamentos, falhas, aporias, incoerências, incompletudes, a sua suspeita do acabado, do integral e do controle é uma espécie de equivalente intelectual de um compromisso vagamente esquerdista para com o oprimido, e como ocorre em todos esses compromissos, exibe perplexidade quando aqueles que defende chegam ao poder. (EAGLETON, 2008, p. 86-87, tradução nossa).
\end{abstract}

Desagrada a Eagleton a proposta de um marxismo que, colocando em segundo plano toda e qualquer ação histórica programada para obter mudanças, acaba paralisado na esperança de um porvir impensável e imprevisível. Derrida reconhece, mas parece não levar suficientemente a sério, a proposta marxista original de um internacionalismo em luta contra a opressão. Reconhece explicitamente, como lembra Eagleton, que "nenhum grau de progresso permite que ignoremos que em nenhum momento anterior, em números absolutos, tantos homens, mulheres e crianças foram subjugados, condenados à fome, ou exterminados na terra" (DERRIDA apud EAGLETON, 2008, p. 87, tradução nossa). Tendo apontado para tais horrores da história contemporânea, contudo, propõe um novo internacionalismo "sem status, sem título, sem partido, sem país, sem uma comunidade nacional”.

Em resposta não apenas a Eagleton, mas a toda uma tradição marxista preocupada em defender com unhas e dentes a materialidade histórica e denunciar qualquer ameaça 
idealizadora ou milagrosa de um porvir que venha a comprometer a história de homens e mulheres penosamente construída no dia a dia, Derrida afirma que a lógica da oposição binária entre materialidade histórica e porvir imaterial não é aquela que exclui e incompatibiliza os termos, mas sim aquela que os torna indissociáveis. Não se trata de uma lógica de isto ou aquilo, mas de isto $e$ aquilo. Na expressão "um marxismo sem classes sociais" ou "sem cidadania" (que Eagleton lê como "marxismo sem marxismo"), a preposição "sem" não deve ser lida apenas em seu sentido negativo de exclusão:

\begin{abstract}
Seria ridículo expressar surpresa a respeito do fato de que uma Internacional (até mesmo a velha Internacional) pudesse constituir-se 'sem' referência à cidadania. $\mathrm{O}$ 'sem' não tem nada de negativo em si e não significa de forma nenhuma que os cidadãos que aderem a essa internacional deixem de ser, em outro nível, cidadãos. O mesmo pode ser dito sobre classe e partido, mesmo no momento em que "partido" e "classe" já não constituem referências maiores ou paradigmas dominantes. (DERRIDA, 1999, p. 252, tradução nossa)
\end{abstract}

Derrida não ignora, portanto, as forças temporais que podem ativar mudanças históricas no aqui e agora e obter resultados mais ou menos significativos em termos de avanço no sistema político ou democrático. Mas não abre mão de avaliar tais forças históricas calculáveis como secundárias em relação ao vigor de um porvir que, imprevisível e incalculável, escapa a qualquer representação no presente. "O que está em questão" diz Derrida, "não é eliminar ou negar associações de classe ou cidadania ou partidos, mas sim apelar para uma Internacional que tenha como fundamento essencial ou força motriz não uma classe, a cidadania ou o partido" (DERRIDA, 1999, p. 252, tradução nossa). E é também esse julgamento de valor que, ao mesmo tempo em que reconhece, mas coloca em segundo plano a presença de forças históricas, preocupa também os defensores da interferência humana no aqui e agora das crises na política e na democracia. E decisões devem ser feitas entre um valor e outro. Vincent Leitch fala por muitos quando afirma que

A famosa invocação da Nova Internacional emergente nos Espectros de Marx, profundamente avessa a percepções, permanece instigante, mas é excessivamente abstrata. Vou continuar a frequentar o Fórum Social Global enquanto espero pela chegada da Nova internacional de Derrida. (LEITCH, 2007, p. 246, tradução nossa). 


\section{REFERÊNCIAS}

BORRADORI, Giovanna. Philosophy in a time of terror: Dialogues with Jürgen Habermas and Jacques Derrida. Chicago: University of Chicago Press, 2003.

DERRIDA, Jacques. Faith and Knowledge: The Two sources of 'Religion' and the Limits of Reason Alone. Acts or Religion, New York, n. 27, p. 65-92, 2002.

DERRIDA, Jacques. The gift of death. Chicago: The University of Chicago Press, 1995.

DERRIDA, Jacques; ROUDINESCO, Elizabeth. De quoi demain: Dialogue. Paris: Galilée, 2001.

DERRIDA, Jacques. Voyous. Paris: Galilée, 2003.

DERRIDA, Jacques. Without alibi. Trad. Peggy Kamuf. Stanford: The University of California Press, 2002.

DERRIDA, Jacques. Marx \& Sons. In SPRINKER, Michael (Ed.). Ghostly demarcations. London: Verso, 2008.

EAGLETON, Terry. Marxism without Marxism. In SPRINKER, Michael (Ed.). Ghostly demarcations. London: Verso, 2008.

KOSELLECK, Reinhart; RICHTER, Michaela. Crisis. Journal of the History of Ideas, Philadelphia, v. 67, n. 2, p. 357-400, Abr. 2006.

LEITCH, Vincent. The Politics of Sovereignty. Critical Inquiry, Chicago, v. 33, n. 2, p. 229247, Winter 2007.

NOBLE, David F. The religion of technology. London: Penguin, 1999.

PAINE, Thomas. The righs of man. Mineola, N.Y.: Dover Publications, 1999.

TERDIMAN, Richard. Determining the Undetermined: Derrida's "University without Condition”. Eighteenth-Century Studies, 2007, v. 40, n. 3. p. 425-441. 